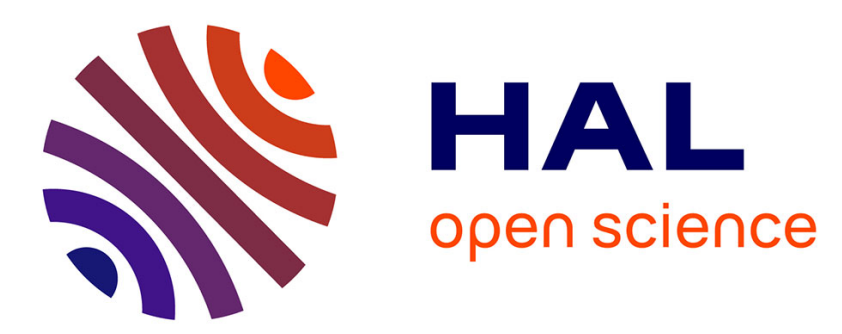

\title{
Beyond analogy: A model of bioinspiration for creative design
}

Armand Hatchuel, Camila Freitas Salgueiredo

\section{To cite this version:}

Armand Hatchuel, Camila Freitas Salgueiredo. Beyond analogy: A model of bioinspiration for creative design. AI EDAM, 2016, 30, pp.159 - 170. 10.1017/S0890060416000044 . hal-01396212

\section{HAL Id: hal-01396212}

https://hal-mines-paristech.archives-ouvertes.fr/hal-01396212

Submitted on 6 Dec 2016

HAL is a multi-disciplinary open access archive for the deposit and dissemination of scientific research documents, whether they are published or not. The documents may come from teaching and research institutions in France or abroad, or from public or private research centers.
L'archive ouverte pluridisciplinaire HAL, est destinée au dépôt et à la diffusion de documents scientifiques de niveau recherche, publiés ou non, émanant des établissements d'enseignement et de recherche français ou étrangers, des laboratoires publics ou privés. 


\section{Beyond analogy: A model of bio-inspiration for creative design}

Camila Freitas Salgueiredo $o^{1,3,4^{*}}$

Armand Hatchuel ${ }^{2}$

1. Renault, Technocentre Guyancourt, Guyancourt, France

2. MinesParisTech- PSL Research University, CGS, CNRS I3 UMR 9217.

3. LIVIC - COSYS, IFSTTAR, Versailles, France

4. Sorbonne Universités, UPMC Univ Paris 06, UMR 722, ISIR, Paris, France

*Corresponding author:

Camila Freitas Salgueiredo

LIVIC-COSYS IFSTTAR

25 allée des Marronniers

F-78000 Versailles, France

Email: camila.freitassalgueiredo@ens.univ-evry.fr

Short title: A model of bio-inspiration for creative design

Number of pages: 27 (without figures)

Number of tables: 2

Number of figures: 6 


\section{Beyond analogy: A model of bio-inspiration for creative design}

\section{Abstract}

Is biologically inspired design only an analogical transfer from biology to engineering? Actually, nature does not always bring "hands-on" solutions that can be analogically applied in classic engineering. Then, what are the different operations that are involved in the bioinspiration process and what are the conditions allowing this process to produce a bioinspired design? In this paper we model the whole design process in which bioinspiration is only one element. To build this model we use a general design theory, Concept-Knowledge (or C-K) theory, because it allows one to capture analogy as well as all other knowledge changes that lead to the design of a bioinspired solution. We ground this model on well described examples of biologically inspired designs available in the scientific literature. These examples include Flectofin ${ }^{\circledR}$, a hingeless flapping mechanism conceived for façade shading, and WhalePower technology, the introduction of bumps on the leading edge of airfoils to improve aerodynamic properties. Our modelling disentangles the analogical aspects of the biologically inspired design process, and highlights the expansions occurring in both knowledge bases, scientific (non-biological) and biological, as well as the impact of these expansions in the generation of new concepts (concept partitioning). This model also shows that bioinspired design requires a special form of collaboration between engineers and biologists. Contrasting with the classic one-way transfer between biology and engineering that is assumed in the literature, the $\mathrm{C}-\mathrm{K}$ framework shows that these collaborations must be "mutually inspirational", because both biological and engineering knowledge expansions are needed to reach a novel solution.

\section{Keywords}

Biologically inspired design;

Concept-Knowledge Design theory;

Innovation; 


\section{Introduction}

Biologically inspired design (BID), also called biomimetic design or biomimicry refers to the use of biological systems as a source of inspiration for improving or developing new technical systems (Vincent et al. (2006), Shu et al. (2011)).

Numerous examples of biomimetic design are found in different fields, such as materials, artificial intelligence, construction or transportation (Bhushan (2009), Bar-Cohen (2012)). According to the Velcro company website, George de Mestral, a Swiss engineer, developed Velcro ${ }^{\circledR}$ based on the observation of burdock plants that attached to his dog fur. Genetic and ant colony optimization algorithms were inspired by natural selection and ant foraging, respectively. The Mercedes Bionic Car, a concept car presented in 2005 , had the boxfish as a model for improving aerodynamic performance and the bio-inspired optimization methods such as Soft Kill Option (Baumgartner et al. (1992)) for improving the vehicle structure (Vincent et al. (2006)). Besides, some researchers consider that natural systems are potential analogies for designing more sustainable systems, as they are submitted to natural selection and evolve in conditions respecting life (Benyus (1997)).

These examples of innovative designs and the need for more sustainable products motivate research and development to integrate the biologically inspired design approach to their new product development process, mainly in the ideas generation phase. This trend is reflected in the growing number of patents (Bonser (2006)) and articles (Lepora et al. (2013)) in this field. Understanding the advantages and limitations of adding biological knowledge into the design process, together with the organization of this process acquires a new significance: which interactions will be established between the different actors of the process (biologists, engineers, and researchers) and what will bring these dialogs between the different knowledge bases involved?

Literature has studied the biologically inspired design from the analogical transfer perspective. The biologically inspired design is interpreted as an analogical transfer between biology and engineering for problem solving (Mak and Shu (2008), Helms et al. (2009), Vattam et al. (2010), Sartori et al. (2010)). 
(Helms and Goel (2012)) recognize that these analogies can also provoke an evolution of the problem. However, this analogical transfer does not allow to disentangle the roles of biological knowledge in the BID process: is it only used as an analogue model or has it effects on the creativity of the generated ideas? Where does this creativity come from? In this paper, Concept-Knowledge (C-K) theory is used to model the biologically inspired design process of selected biomimetic development examples. The aim of this modelling is to provide a framework for understanding not only the analogical processes taking place on biologically inspired design, but also the roles of biological knowledge and scientific knowledge in the process. In this paper, "scientific knowledge" refers to the non-biological knowledge used in the design process such as engineering knowledge. This better understanding of the process can contribute to a more systematic application of biologically inspired design in the ideas generation phase of new product development.

The remainder of the paper is organized as follows: Section 2 provides an overview of the biologically inspired design process theories and tools, identifying the points for which a general design theory could bring some new insights. Section 3 describes the methodology used to analyse biologically inspired design with a design theory. Section 4 presents the analysis of bio-inspired examples from literature using the C-K framework. Section 5 discusses the outcomes from this modelling process and Section 6 concludes the paper.

\section{Theoretical background}

By definition, biologically inspired design bridges two domains: biology and design. Two directions, or "high-level analogical processes for biologically inspired design" (Goel et al. (2014)) were identified for biologically inspired design. These directions refer to the motivations for seeking analogies between nature and design. If the analogical transfer is triggered by an existing design problem, the process is called top-down (Speck and Speck (2008)), problem-driven (Helms et al. (2009), Nagel et al. (2014)) or challenge-to-biology (Biomimicry3.8 (2014)). On the other hand, if a biological phenomenon allows the identification of a design problem that could be solved using an analogy to this phenomenon, 
the process is named bottom-up (Speck and Speck (2008)), solutions-based (Helms et al. (2009), Nagel et al. (2014)) or biology-to-design (Biomimicry3.8 (2014)).

(Sartori et al. (2010)) and (Badarnah and Kadri (2014)) compared studies discussing these approaches, identifying the main steps for each direction, summarized in Table 1.

Table 1: General steps for the biologically inspired design process

\begin{tabular}{llll}
\hline $\begin{array}{l}\text { (Sartori et al. (2010)) } \\
\text { General process }\end{array}$ & General process & Problem-Driven & Solution-based \\
\hline Formulate search & Challenge Definition & Problem definition & Biological domain \\
objectives & & & \\
Search and analyse & Exploration and & Transfer phase & Function (exploration and \\
biological analogues & investigation & & investigation); Analogy and \\
& & & abstraction \\
Transfer & Solution development & Technological domain & Emulation \\
\hline
\end{tabular}

These comparisons highlight the interpretation of BID as an analogical transfer process and the search for biological analogues and transfer are steps found in both directions.

Different studies about the BID process characterized this bridge as an "analogical transfer" or “cross-domain analogies" between biology and engineering (Helms et al. (2009), Cheong and Shu (2013)). The search for biological analogues and the transfer of attributes from the source to the target domain (in the case of BID from biology to design) constitute the two main foci of the research about the biologically inspired design process (Shu et al. (2011)).

In the search for biological analogues, tools such as databases (Deldin and Schuknecht (2014)), ontologies (Vincent (2014)), research on texts written in natural-language format (Chiu and Shu (2007), Shu (2010)), computational tools such as webcrawling (Vandevenne et al. (2013)) and the functional basis (an organized search tool and engineering to biology thesaurus) (Nagel and Stone (2012)) have 
been proposed. These tools depend on the contents of the databases and the designers ability in manipulating the data sources that will be used during the BID process.

For improving the analogical transfer outcome, representations of biological systems in a structure-behavior-function model (SBF) were developed using a platform that has algorithms for indexing and retrieving these models (DANE - Design by Analogy to Nature Engine, (Wiltgen et al. (2011))). The SAPPhIRE model has also been studied for facilitating the analogical transfer in bioinspired design (Sartori et al. (2010)). Other authors proposed functional decomposition to facilitate the identification of transferable attributes (Nagel et al. (2010), Helfman Cohen et al. (2014)). Causal relation templates were proposed by (Cheong and Shu (2013)) in order to facilitate the analogical reasoning when designers use text descriptions of biological phenomena. The Bio-TRIZ approach (Vincent et al. (2006)) uses a modified TRIZ matrix of contradictions, made from the analysis of numerous biological phenomena to identify relevant principles in natural systems that could be used for solving a problem contradiction. Considering the whole BID process, (Goel et al. (2015)), elaborated a Design Study Library, containing case studies of BID from the initial idea until the conceptual design, which could be useful for helping novice designers learning about the BID process.

\subsection{The role of "anomalies" in biologically inspired design}

(Mak and Shu (2008)) identified four similarity types between the source (a biological phenomenon) and the target (the design) in the biologically inspired design process: (i) analogy: "implementation of the strategies found in the biological phenomenon without transferring biological forms"; (ii) literal implementation of biological forms and behaviours; (iii) biological transfer, that keeps the form, using it with a different purpose; (iv) anomaly, when there is no apparent similarity between the concept and the source biological phenomena. Apart from analogy, the other similarity types are considered "errors" (Helms et al. (2009), Shu et al. (2011)). However, (Wilson et al. (2010)) observed that the novelty of designers' ideas was increased when they were exposed to biological examples and only half of these designs had an attribute transferred from the biological system. This may indicate that the biological example have provoked a cognitive stimulation on designers, which was useful to increase novelty. This represents an additional role of the biological knowledge in BID. 


\subsection{Problem evolution in biologically inspired design and the role of analogies}

(Helms and Goel (2012)) proposed a model of analogical problem evolution that takes place during the BID process: a problem definition may evolve (extending or expanding) with the help of an analogy to an already existing solution. Analogies are then able to expand a problem, by adding other dimensions to the problem. Nevertheless, a biological phenomenon could provide the designer analogies that are not useful for his problem, but that could be valuable for solving another problem for which solutions were not specifically being searched for. This case can be found in companies covering large innovation fields, such as the automotive industry, for example.

\subsection{Biologically inspired design goes beyond analogies?}

Analogical transfer is indeed a part of the biologically inspired design process. Many of the bioinspired developments have clear analogies to the biological systems from which they drew inspiration from, namely when they are inspired by forms or "more visible" properties. However, as some studies in literature have pointed out, the biologically inspired design may go beyond analogies: explaining the increase in novelty provoked by the exposure to biological examples (Wilson et al. (2010)) or explaining how the misapplied analogies that involve identification of other knowledge bases, not originally related to the problem to be solved are also useful for stimulating creativity and innovation require the use of a more general design theory, capable of modelling creativity and cognitive stimulation processes.

Design theories have different levels of generativity, the ability to go beyond the search in a fixed set of solutions, and robustness capacity, the ability of producing robust designs (designs that have the expected performances). In order to model generativity and robustness, the tools used by formal design theories can change. To capture generativity it is important to model the expansion process, linked to searching outside a fixed set of solutions, while robustness is described by the ability of the design to resist to a disturbance (Hatchuel et al. (2011b)). The C-K theory (Hatchuel and Weil (2009)) allows a general interpretation of the design process, taking into account the generativeness and robustness capacities. This theory has already been used to disentangle properties from other design theories or methods, such as the creation of creative solutions using ASIT (advanced systematic inventive thinking) (Reich et al. (2012)), the creativity process of Infused Design (Shai et al. (2013)) or the innovative 
properties of Parameter Analysis (PA) (Kroll et al. (2014)). In the creativity domain, it has been used to explain fixation effects (Hatchuel et al. (2011a), Agogué et al. (2014)).

\section{Research methodology: Analysis of biologically inspired design examples with $\mathrm{C}-\mathrm{K}$ theory}

Our research methodology involves the search for examples of biologically inspired design developments (products or processes) in literature. The descriptive accounts of the biologically inspired design process were used to model the bioinspiration process using the $\mathrm{C}-\mathrm{K}$ theory framework and operators. This modelling of the case-examples with the C-K theory required a full description of the design process, including the concept paths not followed and the usual design paths and knowledge bases accessed.

The examples were identified using a systematic research in scientific databases such as Scopus ${ }^{\circledR}$ and journals and books dedicated to biological inspiration such as Bioinspiration and Biomimetics (IOP Publishing), (Bar-Cohen (2012)) book and Design and Nature Conference Proceedings (WIT Press). The search queries were bioinspir*, biologically inspired, biomim*. Among the numerous examples of biologically inspired developments, we chose five examples, in which the bioinspiration process was clear and fully explained.

The C-K theory (Hatchuel and Weil (2003)) defines design as an "interplay between two interdependent spaces", the space of concepts $(\mathrm{C})$ and the space of knowledge $(\mathrm{K})$. The space $\mathrm{K}$ contains the available knowledge of designers. The space $\mathrm{C}$ contains concepts, propositions that are neither true nor false considering the available knowledge in K. Design proceeds by the expansion of the initial concept into other concepts (concept partitioning) and / or into new knowledge, until a partitioned concept becomes a true proposition in K. These two spaces can expand and have different structures. In C space only partitioning (which means adding or subtracting properties) is allowed, giving it a tree-like structure, in which each node represents a partition into several sub-concepts. The K space grows like an "archipelago", with new propositions being added without following an order or a direct connection (Hatchuel and Weil (2009)). 
The transformations between and inside spaces are called operators in C-K. These operators have different functions (Hatchuel and Weil (2009)). The $\mathrm{C} \rightarrow \mathrm{K}$ operator searches attributes in $\mathrm{K}$ that can be used to partition concepts in $\mathrm{C}$ or that contribute to the generation of new propositions in $\mathrm{K}$. The modification of an initial concept by a new attribute must be followed by a verification determining whether the new proposition is still a concept or has become knowledge. The $\mathrm{K} \rightarrow \mathrm{C}$ operator generates new concepts by assigning new attributes to the existing concepts. The $\mathrm{C} \rightarrow \mathrm{C}$ operator allows the analysis of design paths and the $\mathrm{K} \rightarrow \mathrm{K}$ operator represents the classic types of reasoning.

The key notion of C-K theory for the analysis of the BID process is the notion of expanding partitions. These partitions expand the definition of an object, by introducing properties that are not known properties of the object. In addition to the revision of the identity of the object, expanding partitions guide the expansion of knowledge in new directions. Using the example of conceiving new car tires (Hatchuel et al. (2012)), the partition "tires without rubber" is considered expansive. If the partition was already known in K, "tires with white rubber" it would be considered a restricting partition, as it only selects knowledge without simultaneously allowing knowledge expansion. The expanding partitions capture usual processes of creativity, such as inspiration, imagination, analogies and metaphors.

\section{Results: A C-K model for biological inspiration}

From our initial screening of examples in literature on biologically inspired design, we selected five examples to interpret using the $\mathrm{C}-\mathrm{K}$ framework, operators and the expanding partitioning notion. These five examples are: Flectofin ${ }^{\circledR}$, developed by the Institute of Building Structures and Structural Design (IKTE) of the University of Stuttgart and the Plants Biomechanic Group of the University of Freiburg, in Germany; WhalePower technology, conceived by Dr. Frank Fish and Dr. Philip Watts from West Chester University in the United States; the textiles inspired by the Pine-Cone effect developed by Julian Vincent of the University of Bath and Veronika Kapsali from the London College of fashion, the Gecko effect, that allowed the development of different bio-inspired designs, studied in many 
laboratories around the world and the Lotus-Effect, first characterized by (Barthlott and Neinhuis (1997)) and used in self-cleaning coatings and surfaces.

\subsection{Cases overview}

Modelling each case using a C-K framework required the identification of the following aspects of the design process:

- Aspect 1: The technical issue addressed by the biomimetic development (first concept or design path);

- Aspect 2: The biological property observed that could bring some insight for this issue (the biological inspiration);

- Aspect 3: The reasons for using inspiration from nature (how the biological inspiration was used during the design process).

Table 2 summarizes these three aspects for each case. These aspects were used in the construction of the C-K representation of each design process. In this article we detail two of these representations, the WhalePower case and the Flectofin ${ }^{\circledR}$ case. This last C-K framework, along with the framework of the Gecko and Lotus case were presented in a previous study (Freitas Salgueiredo and Hatchuel (2014)), and is now revised and expanded with a clear identification of the expanding partitions and the construction of the knowledge base. With respect to the two directions for biological inspiration, WhalePower represents a case of bottom-up bio-inspiration process and Flectofin ${ }^{\circledR}$ a case of top-down process. 
Table 2: Main aspects identified in each of the case examples of biologically inspired design

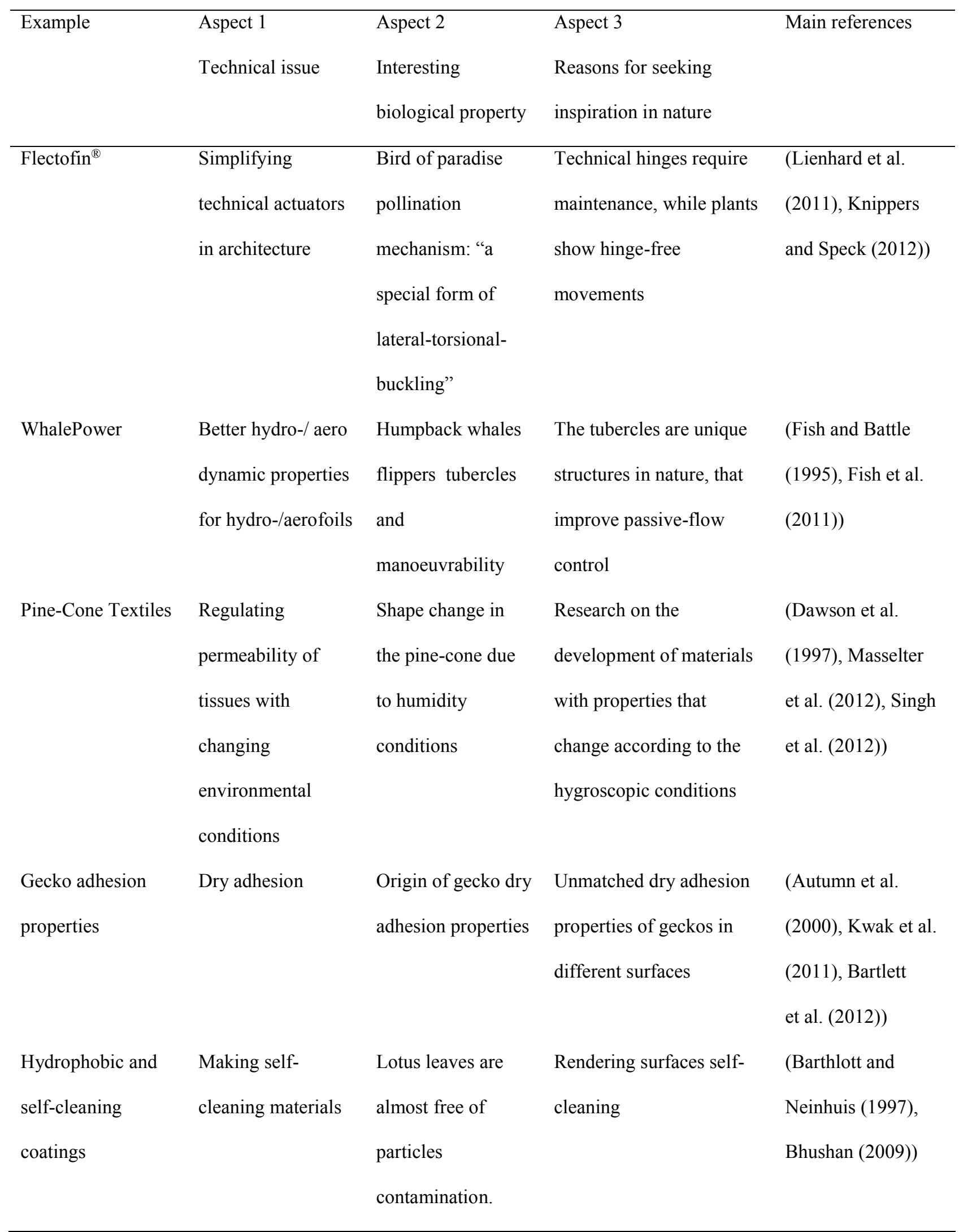




\subsection{C-K modelling of biologically inspired design examples}

The construction of the C-K framework begins with the formulation of concepts linked to the technical issues identified in each case (Aspect 1). Using the information about the biological properties observed, we identified the general biological bases mobilized during the design process (Aspect 2) and the properties from these biological knowledge bases that triggered concept partitioning with the $\mathrm{K} \rightarrow \mathrm{C}$ operator (Aspect 3). We observed that in each case this partitioning had an expanding effect: the concept partitioned using biological knowledge stimulated a revision of the scientific knowledge bases and of the biological knowledge bases.

\subsubsection{Flectofin $^{\circledR}$}

First concept formulation $(K \rightarrow C)$ : Deployable structures with simpler technical actuators are an issue to architects and engineers (Knippers and Speck (2012)). This is a concept in C-K theory: "design of a deployable system with simpler technical actuators", as it cannot be defined only using knowledge available to architects and engineers.

Concepts partitioning $(K \rightarrow C)$ : The usual actuators for deployability use hinges and rollers that require constant maintenance (Lienhard et al. (2011)). One partition for the first concept, formulated using this knowledge about hinges and rollers would be "improving hinges and rollers to require less maintenance".

Biological knowledge activation $(C \rightarrow K)$ and concept partitioning: Previous research of this group had shown that plants have some deployability mechanisms that do not require hinges, and are based on elastic deformations (Matini and Knippers (2008), Lienhard et al. (2009)). The activation of this knowledge base partitions the first concept with "deployable systems in architecture without hinges and rollers", and "using elastic deformations", as it adds new properties to the first concept.

Exploration of biological and scientific knowledge $(K \rightarrow K)$ and concept partitioning: The research group tried to identify deployability phenomena in plants that could be useful for improving deployability in architecture. They explored the biological knowledge on plants deformation without hinges. In parallel, scientific knowledge was also explored: they built prototypes that helped explaining and understanding 
the physical phenomena behind these deformations (Matini and Knippers (2008), Lienhard et al. (2009)). They identified that elastic deformations could be useful for these deployability properties. One of these deployability phenomena, the bird-of-paradise flower pollination mechanism, was identified as particularly interesting to these researchers as it was "actuated externally", making use of "a special form of lateral torsional buckling ... not unfamiliar to engineers but mainly perceived as an undesirable failure mode to be avoided when planning architectural constructions" (Lienhard et al. (2011)). According to (Knippers and Speck (2012)) the external actuation in the bird-of-paradise flower refers to the opening of the two adnate petals that form a perch in which birds can land when searching for the plants' nectar. The mechanical pressure exerted on the perch by the bird causes the bending of the two adnate petals, which exposes the flower pollen. The pollen is attached to the bird's feet, helping the pollination mechanism. When the birds fly away, the perch returns to the closed position.
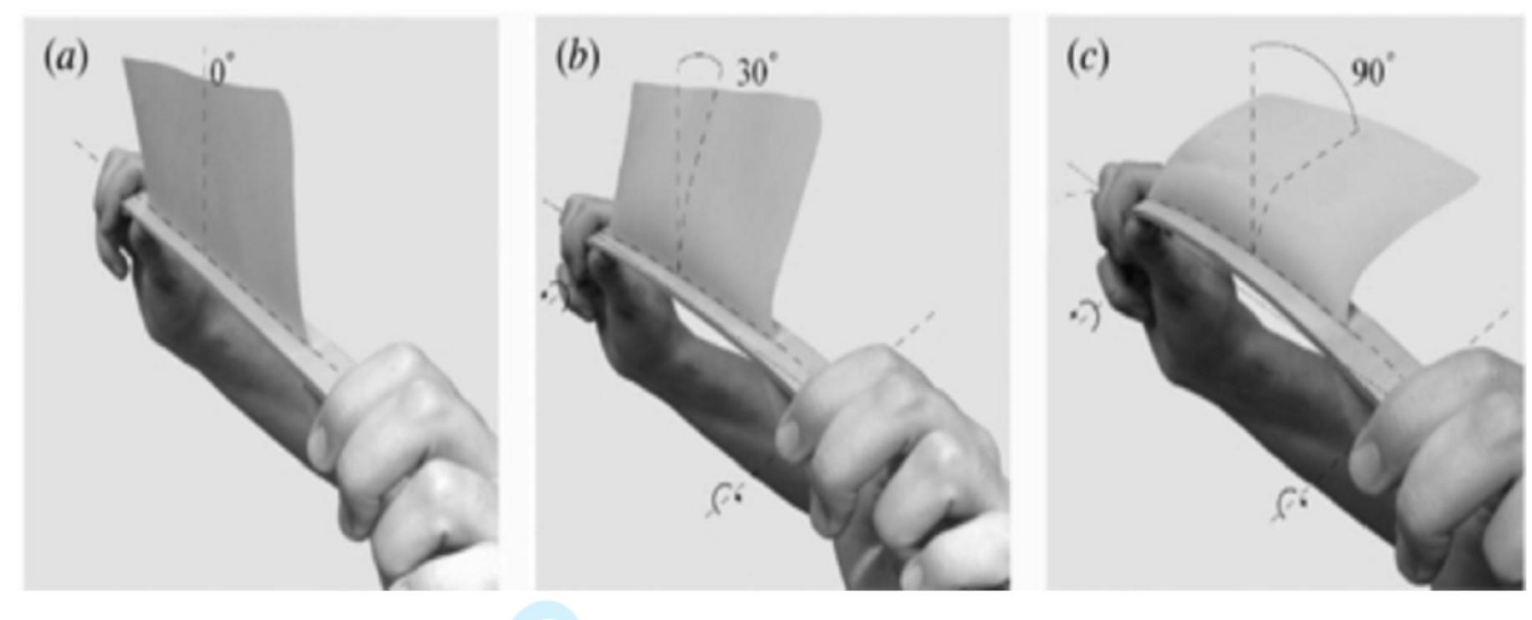

Figure 1: The deformation principle of the bird-of-paradise flower realized with a physical model. The backbone bends by the action of the hands (a) and this deflects the lamina or fin (b) and (c). (Figure 2 from (Lienhard et al. (2011)) (C) IOP Publishing. Reproduced with permission. All rights reserved.) 

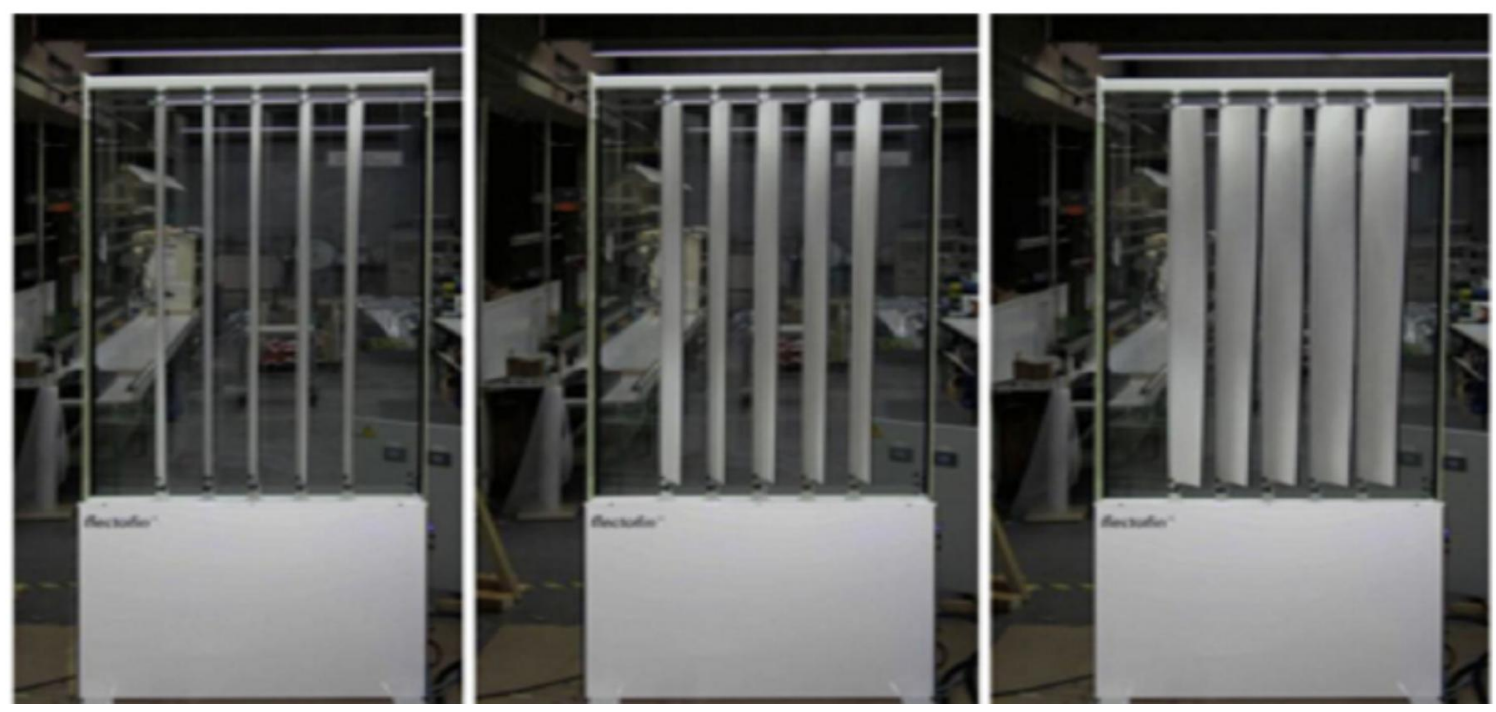

Figure 2: Prototype of the Flectofin ${ }^{\circledR}$ façade shading system (Figure 6 from (Lienhard et al. (2011)) $($ C) IOP Publishing. Reproduced with permission. All rights reserved.)

Scientific knowledge revision $(K \rightarrow K)$ and final design path $(C \rightarrow K)$ : Researchers revised their knowledge about this phenomenon, in order to understand how this failure mode could turn useful for deployable structures. They identified that "attaching a thin shell element to a rib" allowed obtaining this special form of lateral torsional buckling (Figure 1) and studied materials most appropriate for the technical realization, Flectofin ${ }^{\circledR}$, a façade shading system without hinges, has vertical backbones and laminae attached to each backbone (Figure 2). Moving the lower support of the system up and down causes the bending of the backbones and the opening / closing of the laminae (Lienhard et al. (2011), Knippers and Speck (2012)). In this case, the two expanding partitions "without using hinges" and "using lateral torsional buckling" came clearly from the biological knowledge about plants movements and the bird-of-paradise pollination mechanisms.

The C-K framework for this case is summarized in figure 3. 


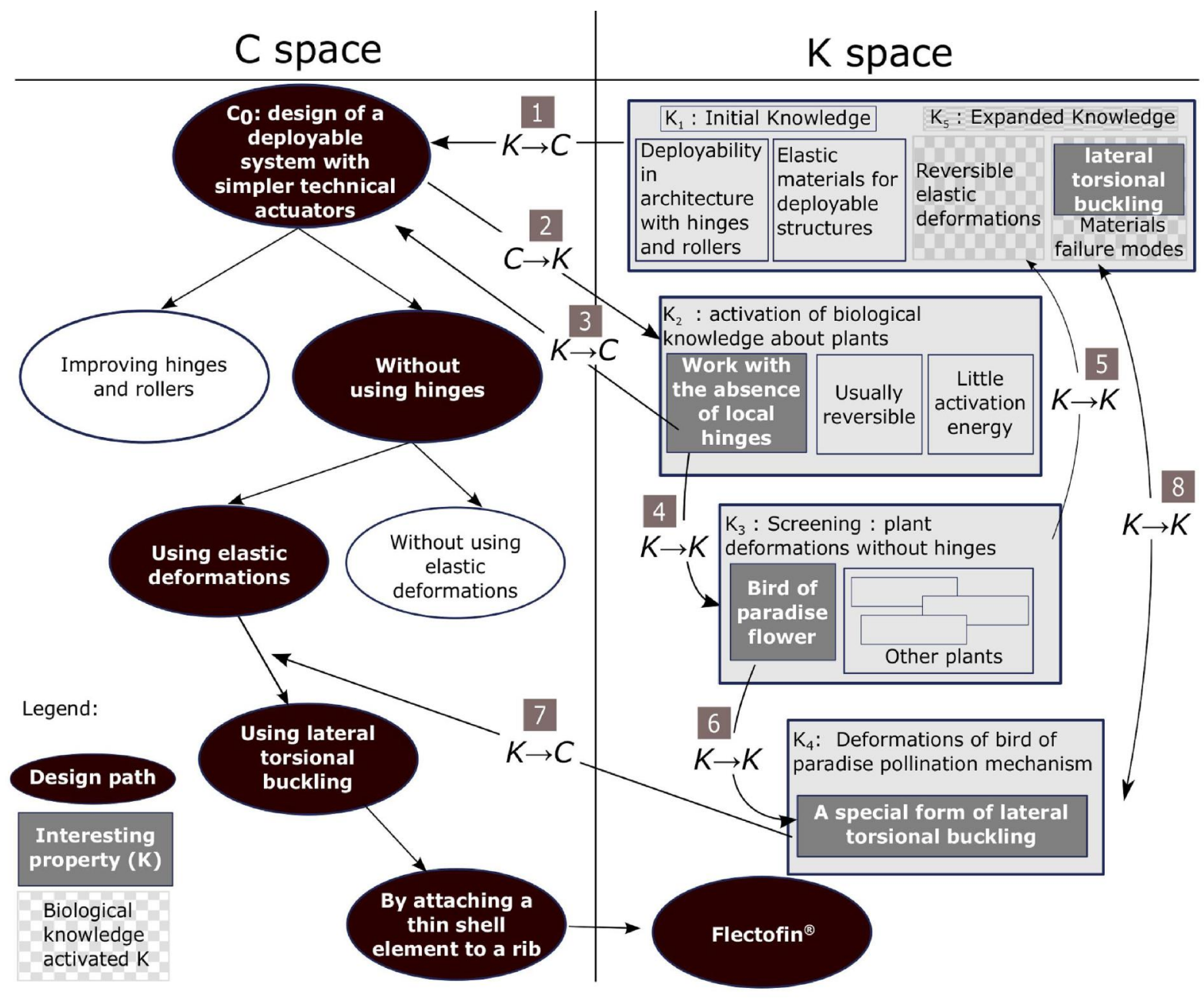

Figure 3: C-K framework for the Flectofin ${ }^{\circledR}$ case

\subsubsection{WhalePower}

First concept formulation $(K \rightarrow C)$ : Humpback whales superior manoeuvrability properties compared to other whales seemed to be linked to their flippers hydrodynamic performance. These flippers have protuberances, called tubercles, on their leading edge, contrasting with the "well-streamlined, engineered hydro and air foils" (Bushnell and Moore (1991), Fish and Battle (1995)). We hypothesize, based on the information presented on the article of (Fish and Battle (1995)), that this contrast between engineering and biology was the starting point for this case. The first concept could then be formulated as the "design of hydro- and airfoils with improved hydro-/aerodynamics properties". 
Concepts partitioning $(K \rightarrow C)$ : the contrast between engineered and biological systems partitions this first concept: "by improving well-streamlined leading edges" and "without using well-streamlined leading edges".

Exploration of biological and scientific knowledge $(K \rightarrow K)$ and concept partitioning: In order to better understand the whale's flippers hydrodynamic properties, researchers activated knowledge about fluid mechanics and hydrodynamics of foils. The concept "without using well-streamlined leading edges" is an expanding partition that allows scientific knowledge about fluid dynamics expansion and revision. Using this newly activated knowledge base, researchers understood the reasons for the improved performance of the tubercles in the leading edges of the whales flipper (Miklosovic et al. (2004), Johari et al. (2007)) and linked tubercles to passive control around a wing like structure (Fish et al. (2011)). The presence of tubercles was claimed to "delay stall and both increase lift and reduce drag at the same time" (Fish et al. (2011)). This was an unexpected property of these structures, that could be applied in the design of hydro and air foils, partitioning the concept of "without well-streamlined leading edges" into "introducing tubercles to the leading edge", not to increase manoeuvrability (as in whales) but to improve hydro and aerodynamics of fan blades, and air turbines.

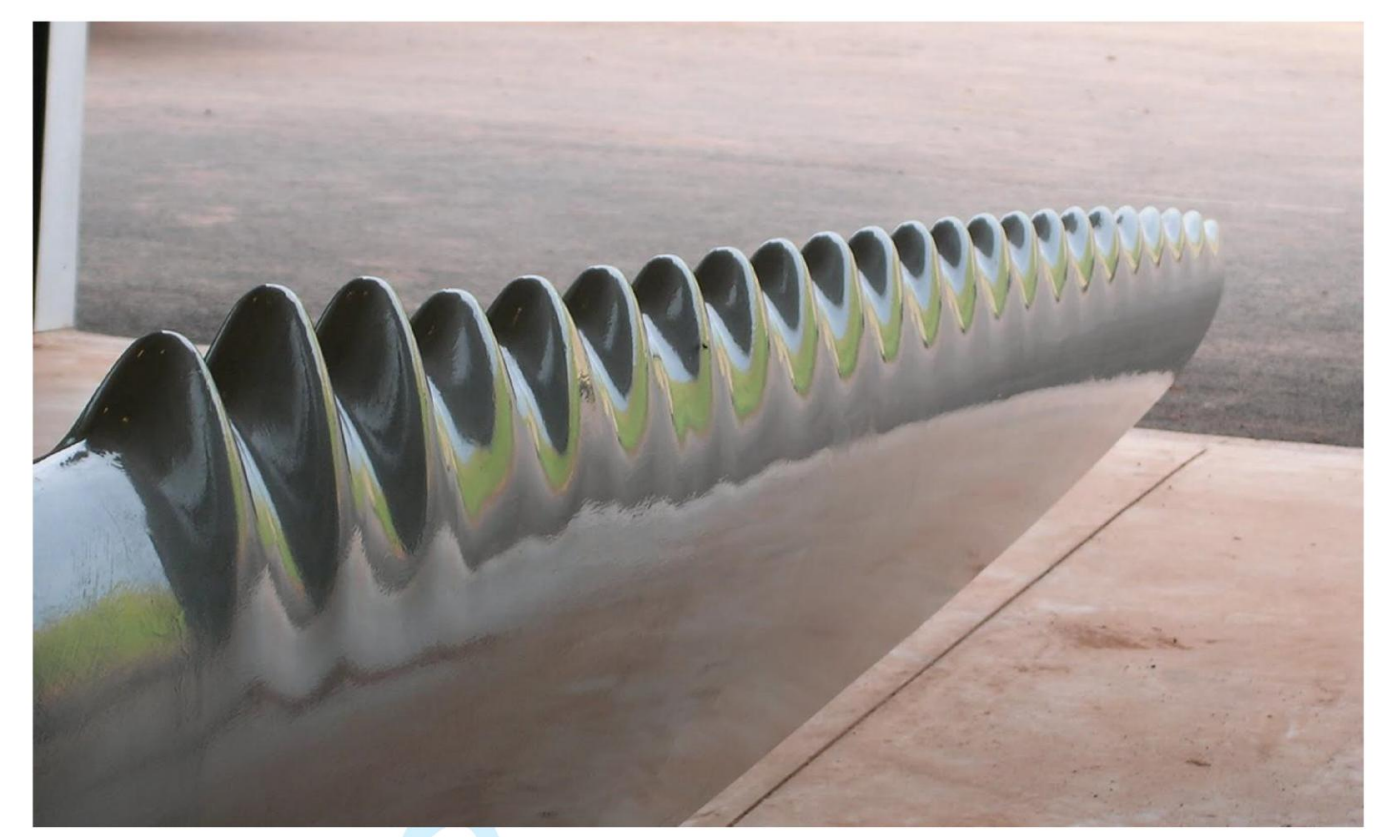

Figure 4: WhalePower technology applied to a turbine blade. Reproduced with permission from Dr. Frank Fish (C) WhalePower Corporation. 
Scientific knowledge revision $(K \rightarrow K)$ and final design path $(C \rightarrow K)$ : The introduction of tubercles in blades of ceiling fans as those currently commercialized by Envira-North (Altra-air fans) represents the final design path. There also current possibilities for applying the bumps in turbines (Figure 4) or in aviation (Fish et al. (2011)).

The C-K framework for this case is summarized in figure 5.

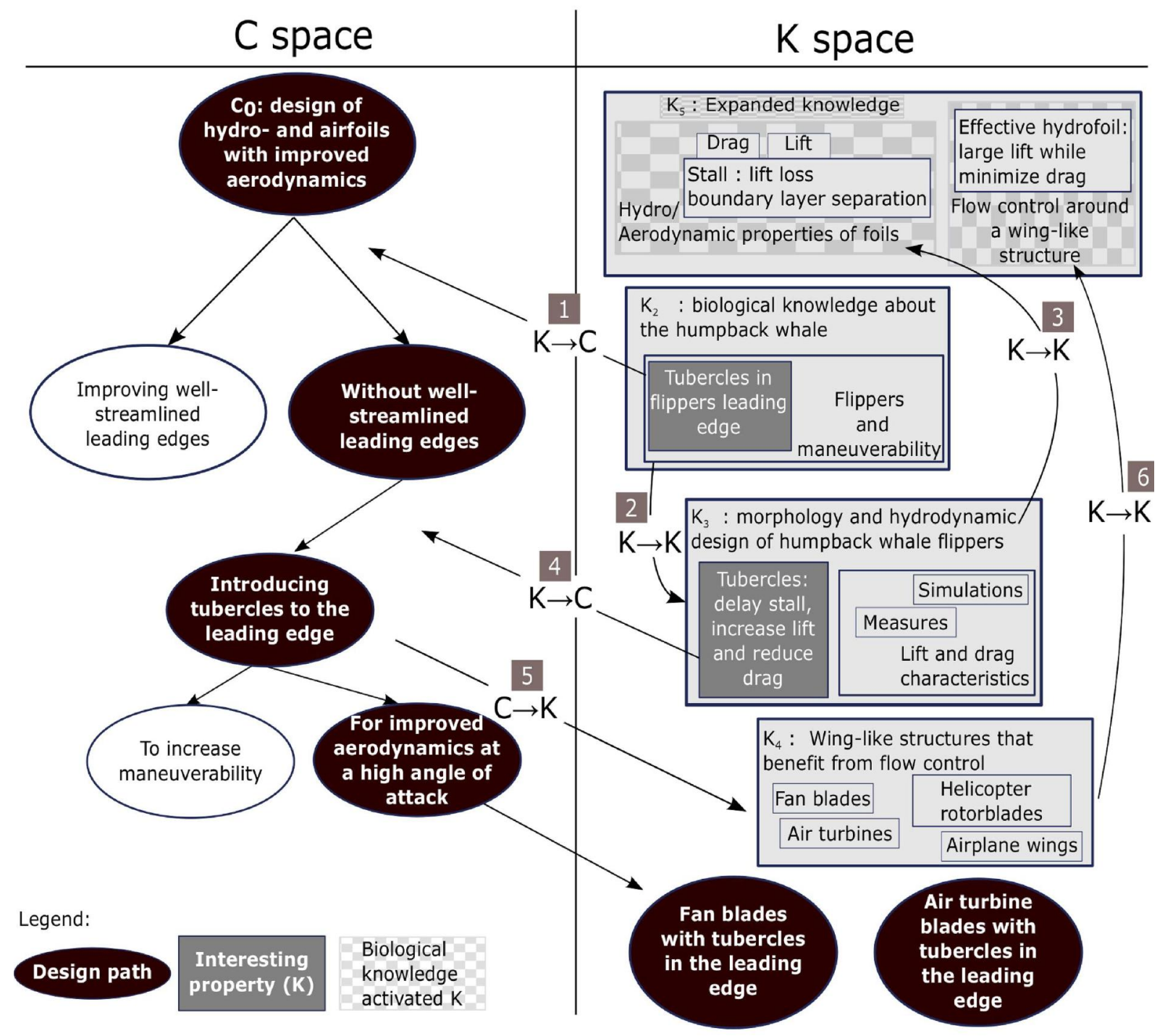

Figure 5: C-K framework for the WhalePower case 


\subsection{A general C-K framework for biologically inspired design}

The previous two examples modelled with the $\mathrm{C}-\mathrm{K}$ framework and operators show some similarities. Firstly, the identification of interesting properties in a biological knowledge base allows the partitioning of concepts of the existing design paths. Secondly, these bio-inspired concepts are expansive concepts: They provoke a revision of the existing knowledge about an object or a phenomena (as in the buckling properties of materials or the aerodynamic properties of foils) and guide the expansion of the knowledge in new directions, activating knowledge bases that would not otherwise be activated.

A general model for BID using the $\mathrm{C}-\mathrm{K}$ framework should then be composed of the two spaces, and the knowledge bases. These knowledge bases are the scientific knowledge bases, i.e. the initial knowledge bases available to designers and the biological knowledge bases, which can exist initially (in the case of WhalePower, biologists were studying the hydrodynamic properties of whales), or not (in the Flectofin ${ }^{\circledR}$ case, architects did not have the biological knowledge at the beginning, but established a partnership with plants biomechanics experts to get access to this knowledge).

The activation of biological knowledge during the design process guides the knowledge expansion phenomena and partitions concepts:

- Scientific knowledge bases are activated to explain or better understand the properties observed in biological phenomena;

- The properties of biological knowledge that activate scientific knowledge bases not spontaneously activated, guide the knowledge revision and expansion and can be conceptualized in the C-space, forming expanding partitions.

These elements can be summarized in the following four general steps, as shown in Figure 6: 


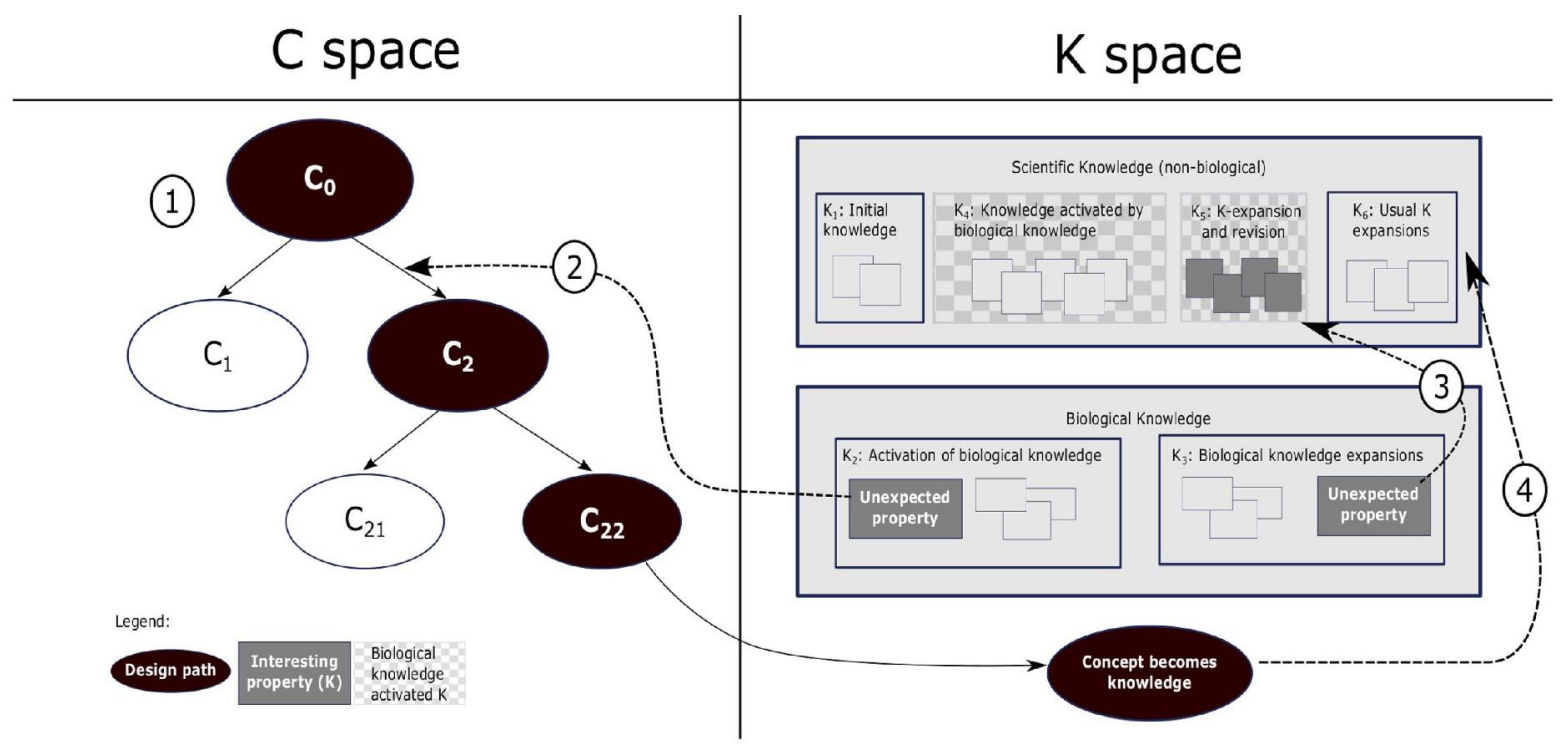

Figure 6: General C-K framework for the biologically inspired design process

1. Identification of design paths for which concept partitioning is required

This identification corresponds to the conceptualization of a design issue that will trigger the activation of scientific knowledge bases for clarifying this issue.

2. Activation of biological knowledge related to the first concept

The choice of the biological knowledge base can be guided by the existing methods for retrieving biological phenomena, such as functional decomposition (Nagel et al. (2010), Helfman Cohen et al. (2014)), SBF modelling (Wiltgen et al. (2011)), the SAPPhIRE model (Sartori et al. (2010)) or search in natural-language (Shu (2010)). Identifying interesting properties partitions the first concept and guides a deeper exploration of the biological knowledge base.

If the observation of an interesting property in a biological system is the starting point of the design process, then the first step becomes the identification of a design path that could benefit from this property.

3. Expansions in both biological and scientific knowledge bases

These expansions represent the activation of biological knowledge (screening process of different plant movements in the case of Flectofin ${ }^{\circledR}$ ) and of scientific knowledge related to these 
interesting biological properties being explored (the modelling and simulations of flippers hydrodynamic properties in the WhalePower case). With these expansions in both knowledge bases, interesting properties allowing concepts partitioning are identified.

4. Return to the scientific knowledge bases

Once a design path becomes knowledge, its development does not depend on the biological knowledge anymore: the pollination mechanism of the bird of paradise flower was useful for understanding how to apply the buckling phenomena, but once researchers understood how to reproduce this phenomena with existing materials and techniques, the development of the product only used scientific knowledge. Similarly, in the WhalePower case, the identification of flippers properties allowed the bumps to be installed in fans, independently from research on whales' movements.

\section{Discussion}

The modelling of the bio-inspired design process with the C-K theory aimed at disentangling the reasons for using biological knowledge during the design process.

The two directions pointed out in literature for the BID process, top-down and bottom-up, are retrieved in the $\mathrm{C}-\mathrm{K}$ framework: the two examples, Flectofin ${ }^{\circledR}$ and WhalePower belong to each one of these directions. The C-K framework gives a more general interpretation to these two directions, not only encompassing the operations in the K space (search for analogues, transfer, and emulation) but also relating these operations to the concepts space, showing that biological knowledge stimulates concepts partitioning and that these partitions are expanding partitions: they guide the exploration and revision of knowledge. These expansions and revisions of both knowledge bases are easily visualized in the C-K framework, facilitating the exploration of the design paths shown in the $\mathrm{C}$ space and the associated knowledge bases.

The creative power of biologically inspired design comes from these expanding partitions it generates, as they stimulate the activation of scientific knowledge bases that would not otherwise be activated. The "interesting" character of biological knowledge is a consequence of this ability to 
generate expansive concept partitioning. This aspect was not easily visualized with the analogical transfer interpretation of the BID process, as it does not show how the analogous properties found in biological systems interact with the existing knowledge and if this interaction stimulates the search of new knowledge bases or if it leads to remaining in the same knowledge bases.

The C-K model for BID also provides some insights about the organization of this process in practice. Firstly, the $\mathrm{C}-\mathrm{K}$ model indicates that the use of biological knowledge in the design process requires more than a superficial knowledge about biological systems. For example, when designing a novel multi-energy system for vehicles, it is not sufficient to know that nature also has multi-energy systems. Engineers must also understand details about the design of these natural systems, and reinterpret this biological knowledge using their own knowledge bases, and possibly new ones that they will have to acquire. This collaboration between engineering and biology differs from a simple knowledge sharing or transfer process: biology specialists must work together with engineers, also revising their knowledge with the revisions engineers are making, while engineers should be able to accurately identify the knowledge bases that biological knowledge is revising and the new ones being activated.

This $\mathrm{C}-\mathrm{K}$ framework offers a representation of the design process, including the design paths and the use of knowledge bases. It provides designers with a representation of the design paths and how the knowledge bases being activated can interact. Designers can easily see, using this framework, that the biologically inspired design process involves not only finding an interesting property in biology. It implies relating these properties to existing knowledge bases, which can lead to revisions and expansions in these scientific knowledge bases.

One limitation of this C-K model is that it does not indicate how the suitable biological knowledge bases should be found. The methods and tools proposed in literature for the BID analogical transfer could represent a solution to this aspect. For example, functional decomposition (Nagel et al. (2014)) can be used to expand and revise both biological and non-biological knowledge bases, helping in the identification of non-spontaneously activated knowledge bases while natural-language (Shu (2010)) can help in the identification of other biological bases to explore during the design process. However, it is 
important to notice that while classic analogical transfer methods consider misapplied analogies as errors in analogical transfer, the $\mathrm{C}-\mathrm{K}$ framework shows that the most important role of biological knowledge is concept partitioning, independently of these properties being used or not in the final design path.

\section{Conclusions and perspectives}

The interpretation of the biologically inspired design process with the $\mathrm{C}-\mathrm{K}$ theory framework presented in this article highlights two main aspects of this process. The first one refers to the knowledge base construction that takes place during the biologically inspired design process. Two knowledge bases, biological and scientific (non-biological) are expanded and revised during the process. The identification of interesting properties in the knowledge space allowing concept partitioning is made possible only with the expansions in both knowledge bases. The second one is related to the organizational aspects of the BID process. Expanding and revising these two knowledge bases requires a collaboration between biology and traditional engineering, this collaboration is "mutually inspirational" because both knowledge bases are expanded using the interesting properties. Therefore, these interesting properties can only be identified by making connections between the two knowledge bases.

This initial modelling of the biologically inspired design process using the C-K theory framework and operators is based on a limited number of case-examples. This model constitutes a first step towards a comprehension and systematic inclusion of other process besides analogy into the design process.

Future work will elaborate on these findings and explore practical conditions for applying these two findings in a real industrial context. 


\section{References}

Agogué, M., Kazakçi, A., Hatchuel, A., Le Masson, P., Weil, B., Poirel, N., Cassotti, M., 2014. The impact of type of examples on originality: Explaining fixation and stimulation effects. The Journal of Creative Behavior 48 (1), 1-12.

Autumn, K., Liang, Y. A., Hsieh, S. T., Zesch, W., Chan, W. P., Kenny, T. W., Fearing, R., Full, R. J., 2000. Adhesive force of a single gecko foot-hair. Nature 405, $681-684$.

Badarnah, L., Kadri, U., 2014. A methodology for the generation of biomimetic design concepts. Architectural Science Review, 1-14.

Bar-Cohen, Y., 2012. Biomimetics: nature based innovations. CRC press.

Barthlott, W., Neinhuis, C., 1997. Purity of the sacred lotus, or escape from contamination in biological surfaces. Planta 202, 1-8.

Bartlett, M. D., Croll, A. B., King, D. R., Paret, B. M., Irschick, D. J., Crosby, A. J., 2012. Looking beyond fibrillar features to scale gecko-like adhesion. Advanced Materials 24 (8), 1078-1083.

Baumgartner, A., Harzheim, L., Mattheck, C., 1992. \{SKO\} (soft kill option): the biological way to find an optimum structure topology. International Journal of Fatigue 14 (6), 387 - 393.

Benyus, J. M., 1997. Biomimicry: innovation inspired by nature. William Morrow and Co.

Bhushan, B., 2009. Biomimetics: lessons from nature - an overview. Philosophical Transactions of the Royal Society A: Mathematical,Physical and Engineering Sciences 367 (1893), 1445-1486.

Biomimicry3.8, 2014. Biomimicry design lens: Biomimicry thinking. Electronic, accessed on 14.10.2014. http://biomimicry.net/about/biomimicry/biomimicry-designlens/biomimicry-thinking/

Bonser, R. H., 2006. Patented biologically-inspired technological innovations: A twenty year view. Journal of Bionic Engineering 3 (1), $39-41$.

Bushnell, D. M., Moore, K. J., 1991. Drag reduction in nature. Annual Review of Fluid Mechanics $23(1), 65-79$.

Cheong, H., Shu, L., 2013. Using templates and mapping strategies to support analogical transfer in biomimetic design. Design Studies 34 (6), $706-728$.

Chiu, I., Shu, L., 1 2007. Biomimetic design through natural language analysis to facilitate crossdomain information retrieval. AI EDAM: Artificial Intelligence for Engineering Design, Analysis, and Manufacturing 21, 45-59.

Dawson, C., Vincent, J. F. V., Rocca, A.-M., 1997. How pine cones open. Nature 390 (6661), 668.

Deldin, J.-M., Schuknecht, M., 2014. Biologically inspired design: computational methods and tools. Springer-Verlag, Ch. The AskNature Database: Enagling Solutions in Biomimetic Design, pp. 17-27.

Fish, F. E., Battle, J. M., 1995. Hydrodynamic design of the humpback whale flipper. Journal of Morphology 225 (1), 51-60.

Fish, F. E., Weber, P. W., Murray, M. M., Howle, L. E., 2011. The tubercles on humpback whales' flippers: Application of bio-inspired technology. Integrative and Comparative Biology 51 (1), $203-$ 213.

Freitas Salgueiredo, C., Hatchuel, A., 2014. Modeling biologically inspired design with the c-k theory. In: Proceedings of the DESIGN 2014 conference, Dubrovnik, Croatia. 
Goel, A., Zhang, G., Wiltgen, B., Zhang, Y., Vattam, S., Yen, J., 2015. The design study library: Collecting, analyzing and using case studies of biologically inspired design. In: Gero, J. S., S. H. (Ed.), Design computing and cognition'14. Vol. XIV.

Goel, A. K., Vattam, S., Wiltgen, B., Helms, M., 2014. Biologically Inspired Design: Computational Methods and Tools. Springer-Verlag London, Ch. Information processing theories of biologically inspired design, pp. $127-152$.

Hatchuel, A., Le Masson, P., Weil, B., 12011 a. Teaching innovative design reasoning: How conceptknowledge theory can help overcome fixation effects. AI EDAM: Artificial Intelligence for Engineering Design, Analysis, and Manufacturing 25, 77-92.

Hatchuel, A., Masson, P. L., Reich, Y., Weil, B., 2011b. A systematic approach of design theories using generativeness and robustness. In: Culley, S., Hicks, B., McAloone, T., Howard, T., Reich, Y. (Eds.), Proceedings of the 18th International Conference on Engineering Design (ICED 11), Impacting Society through Engineering Design. Vol. 2. pp. 87-97.

Hatchuel, A., Weil, B., 2003. A new approach of innovative design: an introduction to c-k theory. In: Proceedings of the 14th International Conference on Engineering Design (ICED'03), Stockholm, Sweden. pp. 109-124.

Hatchuel, A., Weil, B., 2009. C-k design theory: an advanced formulation. Research in Engineering Design 19, 181-192.

Hatchuel, A., Weil, B., Masson, P., 2012. Towards an ontology of design: lessons from c-k design theory and forcing. Research in Engineering Design, 1-17.

Helfman Cohen, Y., Reich, Y., Greenberg, S., Oct. 2014. Biomimetics: Structure-Function Patterns Approach. Journal of Mechanical Design 136 (11), 111108.

Helms, M., Goel, A., 2012. Analogical problem evolution in biologically inspired design. In: Gero, J. S. (Ed.), Design Computing and Cognition '12. Springer Netherlands, pp. 3-19.

Helms, M., Vattam, S. S., Goel, A. K., 2009. Biologically inspired design: process and products. Design Studies 30 (5), $606-622$.

Johari, H., Henoch, C. W., Custodio, D., Levshin, A., 2007. Effects of leading-edge protuberances on airfoil performance. AIAA Journal 45, $2634-2642$.

Knippers, J., Speck, T., 2012. Design and construction principles in nature and architecture. Bioinspiration \& Biomimetics 7 (1), 015002.

Kroll, E., Le Masson, P., Weil, B., 2014. Steepest-first exploration with learning-based path evaluation: uncovering the design strategy of parameter analysis with c-k theory. Research in Engineering Design 25 (4), 351-373.

Kwak, M. K., Pang, C., Jeong, H.-E., Kim, H.-N., Yoon, H., Jung, H.-S., Suh, K.-Y., 2011. Towards the next level of bioinspired dry adhesives: New designs and applications. Advanced Functional Materials 21 (19), 3606-3616.

Lepora, N. F., Verschure, P., Prescott, T. J., 2013. The state of the art in biomimetics. Bioinspiration \& Biomimetics 8 (1), 013001.

Lienhard, J., Poppinga, S., Schleicher, S., Masselter, T., Speck, T., Knippers, J., 2009. Abstraction of plant movements for deployable structures in architecture. In: Proceedings of the 6th Plant Biomechanics Conference. pp. 389-397. 
Lienhard, J., Schleicher, S., Poppinga, S., Masselter, T., Milwich, M., Speck, T., Knippers, J., 2011. Flectofin: a hingeless flapping mechanism inspired by nature. Bioinspiration \& Biomimetics 6 (4), 045001 .

Mak, T., Shu, L., 2008. Using descriptions of biological phenomena for idea generation. Research in Engineering Design 19 (1), 21-28.

Masselter, T., Barthlott, W., Bertling, J., Cichy, F., Hermann, M., Knippers, J., Luchsinger, R., Mattheck, C., Milwich, M., Neinhuis, C., 2012. Biomimetics: nature based innovations. CRC press, Ch. Biomimetic Products, pp. 377-429.

Matini, M., Knippers, J., 2008. Application of "abstract formal patterns" for translating natural principles into the design of new deployable structures in architecture. WIT Transactions on Ecology and the Environment, Design and Nature IV, CA Brebbia ed 114, 147-156.

Miklosovic, D. S., Murray, M. M., Howle, L. E., Fish, F. E., 2004. Leading-edge tubercles delay stall on humpback whale (megaptera novaeangliae) flippers. Physics of Fluids 16 (5), L39-L42.

Nagel, J., Stone, R.B., McAdams, D., 2014. Biologically inspired Design: Computational Methods and Tools. Springer-Verlag London, Ch. Function-based Biologically-Inspired Design, pp. 95 - 125.

Nagel, J. K., Nagel, R. L., Stone, R. B., McAdams, D. A., 2010. Function-based, biologically inspired concept generation. AI EDAM: Artificial Intelligence for Engineering Design, Analysis, and Manufacturing 24, 521-535.

Nagel, J. K., Stone, R. B., 5 2012. A computational approach to biologically inspired design. Artificial Intelligence for Engineering Design, Analysis and Manufacturing 26, 161-176. http://journals.cambridge.org/article_S0890060412000054

Reich, Y., Hatchuel, A., Shai, O., Subrahmanian, E., 2012. A theoretical analysis of creativity methods in engineering design: casting and improving asit within c?Äik theory. Journal of Engineering Design $23(2), 137-158$.

Sartori, J., Pal, U., Chakrabarti, A., 2010. A methodology for supporting "transfer" in biomimetic design. AI EDAM: Artificial Intelligence for Engineering Design, Analysis, and Manufacturing 24, 483-506.

Shai, O., Reich, Y., Hatchuel, A., Subrahmanian, E., 2013. Creativity and scientific discovery with infused design and its analysis with c-k theory. Research in Engineering Design 24 (2), 201-214.

Shu, L., 2010. A natural-language approach to biomimetic design. AI EDAM: Artificial Intelligence for Engineering Design, Analysis, and Manufacturing 24 (Special Issue 04), 507-519.

Shu, L., Ueda, K., Chiu, I., Cheong, H., 2011. Biologically inspired design. CIRP Annals Manufacturing Technology 60 (2), $673-693$.

Singh, A. V., Rahman, A., Kumar, N. S., Aditi, A., Galluzzi, M., Bovio, S., Barozzi, S., Montani, E., Parazzoli, D., 2012. Bio-inspired approaches to design smart fabrics. Materials \& Design 36 (0), 829 839.

Speck, T., Speck, O., 2008. Process sequences in biomimetic research. In: Brebbia, C. (Ed.), Design and Nature IV. Vol. 114 of WIT Transactions on Ecology and the Environment,. WIT Press, pp. 3-11.

Vandevenne, D., Caicedo, J., Verhaegen, P.-A., Dewulf, S., Duflou, J., 2013. Webcrawling for a biological strategy corpus to support biologically-inspired design. In: Chakrabarti, A. (Ed.), CIRP Design 2012. Springer London, pp. 83-92. 
Vattam, S. S., Helms, M. E., Goel, A. K., 2010. A content account of creative analogies in biologically inspired design. AI EDAM: Artificial Intelligence for Engineering Design, Analysis, and Manufacturing 24, 467-481.

Vincent, J. F., 2014. Biologically inspired Design: Computational Methods and Tools. SpringerVerlag London, Ch. An Ontology of Biomimetics, pp. $269-285$.

Vincent, J. F., Bogatyreva, O. A., Bogatyrev, N. R., Bowyer, A., Pahl, A.-K., 2006. Biomimetics: its practice and theory. Journal of The Royal Society Interface 3 (9), 471-482.

Wilson, J. O., Rosen, D., Nelson, B. A., Yen, J., 2010. The effects of biological examples in idea generation. Design Studies 31 (2), $169-186$.

Wiltgen, B., Goel, A., Vattam, S., 2011. Representation, indexing, and retrieval of biological cases for biologically inspired design. In: Ram, A., Wiratunga, N. (Eds.), Case-Based Reasoning Research and Development. Vol. 6880 of Lecture Notes in Computer Science. Springer Berlin Heidelberg, pp. 334347. 


\section{Biographies}

Camila Freitas Salgueiredo is currently a PhD Student at the University of Evry and at the LIVICIFSTTAR and ISIR-UPMC laboratories. She worked with the application of biologically inspired design for developing concepts allowing cars carbon dioxide emissions reductions in collaboration with Renault.

Professor Armand Hatchuel is Professor and co-head of the Chair of Design Theory and Methods for Innovation at Mines ParisTech-PSL Research University. He has published extensively and is member of journal and scientific boards. He received several awards. He is fellow of the national academy of technologies and of the Design Society. 


\section{Acknowledgements}

The authors thank the researchers of the Design Theory and Methods for Innovation Research and Teaching Chair; Philippe Doublet from Renault; Drs. Sébastien Glaser, Olivier Orfila, and Guillaume Saint Pierre from the LIVIC-IFSTTAR laboratory; Professor Stéphane Doncieux from ISIR-UPMC; and Professor Véronique Billat from UBIAE for their support and feedback throughout this work. 